\title{
Avaliação do Banco de Sementes de uma Área em Processo de Recuperação em Cerrado Campestre ${ }^{1}$
}

\author{
Evaluation of the Seed Bank in a Campestre Cerrado Area under Recovery
}

MACHADO, V.M. ${ }^{2}$, SANTOS, J.B. ${ }^{3}$, PEREIRA, I.M. ${ }^{3}$, LARA. R.O. ${ }^{4}$, CABRAL, C.M. ${ }^{4}$ e AMARAL, C.S. ${ }^{2}$

\begin{abstract}
RESUMO - Os estudos que tratam da interferência de plantas daninhas em agroecossistemas têm produzido resultados de pesquisa abundantes para campos de produção de grãos e pastagens; contudo, poucos trabalhos relatam o efeito da presença desse grupo de plantas em áreas degradadas isoladas para recuperação. Diante disso, este trabalho teve como objetivo avaliar a influência do banco de sementes no solo no processo de restauração ambiental de uma área representativa de cerrado campestre pela presença de plantas daninhas gramíneas. Para avaliação do banco de sementes, foram selecionados três ambientes: dois degradados e um ambiente-referência (conservado) de cerrado campestre. O procedimento de coleta das amostras de solo ocorreu em duas estações (seca e chuvosa), e as amostras foram avaliadas em 300 dias. Foram verificadas, durante a avaliação, apenas seis espécies nativas, e somente duas com hábito de vida arbóreo. A maior parte das sementes germinadas para os ambientes degradados, em ambas as coletas, foram identificadas como invasoras na área de estudo. Nesse sentido, o banco de sementes do solo local não é suficiente para que haja recuperação por meio da sucessão ecológica dessas áreas, sendo recomendado o uso de técnicas visando acelerar a restauração desses ambientes.
\end{abstract}

Palavras-chave: restauração de áreas degradadas, plantas daninhas, Melinis minutiflora.

ABSTRACT - Studies dealing with the interference of weeds in agro-ecosystems have obtained abundant results for grain production fields and pastures. However, few studies have reported the effect of the presence of such a group of isolated plants on degraded areas under recovery. Thus, this study aims to evaluate the influence of the soil seed bank on the process of environmental restoration of a representative area of campestre cerrado due to the presence of weed grasses. To assess the seed bank, three environments were selected: two degraded environments and one reference-environment (preserved) of campestre cerrado. Soil samples were collected in two seasons (dry and wet), and evaluated in three hundred days. During the evaluation, only six native species and only two species with a habit of arboreal life were found. Most of the seeds which were germinated for the degraded environments in both collections were identified as invasive in the study area. In this sense, the local soil seed bank is not considered sufficient for recovery through ecological succession in these areas, and the use of techniques to accelerate the restoration of these environments is strongly recommended.

Keywords: restoration of degraded areas, weeds, Melinis minutiflora.

\section{INTRODUÇÃO}

A crescente demanda pelos recursos naturais - que é motivo do cenário atual das grandes áreas degradadas em todo o país - tem levado à extinção de várias espécies mesmo antes de elas serem reconhecidas. Constantes processos de corte e queima da vegetação para fins agropecuários, dessecação de grandes áreas com glyphosate e exploração de madeira

1 Recebido para publicação em 27.6.2012 e aprovado em 16.9.2012.

2 Mestres em Ciência Florestal pela Universidade Federal dos Vales do Jequitinhonha e Mucuri - PPGCF/ UFVJM,<viniciusfloresta@hotmail.com>, <cristiayamaral@hotmail.com>; ${ }^{3}$ Docentes permanentes, PPGCF/UFVJM, <barbosa@pq.cnpq.br>, <imarinhopereira@gmail.com>; ${ }^{4}$ Mestrandos, PPGCF/UFVJM, <rodrigolara1987@hotmail.com>, $<$ mtchells@yahoo.com.br>. 
e minerais alteram a estrutura natural do ecossistema. Segundo Caldato et al. (1996), o que era para ser um processo lento e equilibrado, a ação antrópica alterou esse equilíbrio e acelerou bruscamente o processo de extinção das espécies.

Os estudos que tratam da interferência de plantas daninhas e agroecossistemas têm produzido resultados de pesquisa abundantes para campos de produção de grãos e pastagens, porém poucos trabalhos relatam o efeito da presença desse grupo de plantas em áreas degradadas isoladas para recuperação.

O bioma cerrado tem apresentado maior pressão antrópica, decorrente principalmente da atividade pecuária (Sano et al., 2002). O efeito dessa antropização sobre as espécies encontradas em áreas originalmente sob vegetação de cerrado pode ser analisado sob o ponto de vista ecológico, como as perdas da riqueza das espécies nativas (Felfili \& Silva Júnior, 2001), e o de produção agropecuária, na qual as espécies nativas que se mantiveram na área agricultável podem ser consideradas invasoras e, assim, comprometer a produtividade agrícola (Pott et al., 2006).

O principal meio de regeneração das espécies, após um distúrbio, dá-se por meio do banco de sementes do solo. Esse banco atua como um reservatório de diversidade genética vegetal que pode ser usado para restaurar zonas perturbadas ou recuperar espécies da flora que estão em via de extinção (Pérez et al., 2001); todavia, é um recurso que deve ser avaliado quanto à sua composição, para evitar a infestação de plantas exclusivamente ruderais.

O banco de sementes no solo é constituído de todas as sementes viáveis nesse compartimento ou associadas à serrapilheira para uma determinada área num dado momento (Simpson et al.,1989). É um sistema dinâmico, com entrada de sementes trazidas pela chuva de sementes e dispersão, podendo ser transitório, com sementes que germinam até um ano depois do início da dispersão, ou persistente, com sementes que permanecem no solo por mais de um ano. Essa persistência corresponde, segundo Simpson et al. (1989), uma reserva do potencial genético acumulado.
A variabilidade e densidade botânica de um povoamento de sementes no solo, em um dado momento, são o resultado do balanço entre entrada de novas sementes e perda por germinação, deterioração, parasitismo, predação e transporte (Carmona, 1992; Price et al., 1997).

Avaliando a composição do banco de sementes, pode-se predizer a composição inicial da vegetação após um distúrbio. As informações sobre o banco de sementes podem subsidiar investigações sobre três aspectos da vegetação: sua composição, a abundância relativa das espécies recentemente instaladas e o potencial de distribuição de cada espécie (Welling et al., 1988). A composição do banco de sementes é função da composição das sementes produzidas pela vegetação e da longevidade das sementes de cada espécie, sob as condições locais (van der Valk \& Pederson, 1989).

A adoção de técnicas de manejo a partir da utilização de banco de sementes pode ser eficaz na restauração de áreas degradadas, porém, para se obter sucesso, é preciso conhecê-lo (Costalonga et al., 2006). No entanto, sua utilização não elimina as incertezas da germinação e sobrevivência das plântulas, uma vez que estas estão associadas às condições ambientais determinantes do sucesso ou não do plano de revegetação (van der Valk \& Pederson, 1989).

A perturbação contínua de uma área pode levar ao esgotamento progressivo do banco de sementes, tornando o local com restrições para regenerar na primeira fase da sucessão. Locais muito abertos e ensolarados propiciam a entrada de propágulos de plantas daninhas gramineas, que impedem a regeneração natural da floresta (Nogueira \& Nogueira, 1991). Nóbrega et al. (2009) observam que, em áreas de florestas, capoeiras e pastos perturbados, foi evidenciado que a diversidade de espécies arbóreas no banco de sementes e, principalmente, das espécies dos estádios mais avançados de sucessão foi reduzida.

O presente trabalho teve como objetivo avaliar a influência do banco de sementes do solo no processo de restauração ambiental de uma área perturbada pela presença de plantas daninhas gramíneas, localizada no Alto do Jequitinhonha, Minas Gerais. 


\section{MATERIAL E MÉTODOS}

A área estudada tem tamanho aproximado de 1 ha e está localizada no município de Diamantina, região do Alto Jequitinhonha, no Complexo da Serra do Espinhaço, Estado de Minas Gerais, situado nas coordenadas geográficas de $18^{\circ} 25^{\prime} 53^{\prime \prime} \mathrm{S}$ de latitude e $43^{\circ} 60^{\prime} 36^{\prime \prime} \mathrm{W}$ de longitude, a uma altitude de $1.130 \mathrm{~m}$. O regime climático é tipicamente tropical - $\mathrm{Cwb}$ na classificação de Köppen -, caracterizado por verões brandos e úmidos (outubro a abril) e invernos mais frescos e secos (junho a agosto). A precipitação pluvial média anual varia de 1.250 a $1.550 \mathrm{~mm}$ e a temperatura média anual situa-se na faixa de $18^{\circ}$ a $19^{\circ} \mathrm{C}$, sendo predominantemente amena durante todo o ano, devido às superfícies mais elevadas dessa serra. A umidade relativa do ar é quase sempre elevada, revelando médias anuais de 75,6\%.

A vegetação predominante na área de estudo pode ser caracterizada como cerrado campestre (Ribeiro \& Walter, 2008).

A área foi isolada em 2002, procedendose posteriormente à restauração ambiental por meio do plantio ao acaso de mudas de espécies exóticas locais (alóctones), como Acacia mangium, Bauhimia variegata, Cedrela fissilis, Ceiba speciosa, Copaifera langsdorffii, Ficus beijamina, Jacaranda mimosifolia, Handroanthus impetiginosus, Handroanthus serratifolius, entre outras, concomitantemente com a semeadura de algumas espécies de gramíneas, como Melinis minutiflora e Urochloa decumbens, com o simples objetivo de recobrir o solo e protegê-lo contra o processo erosivo.

Para avaliação do banco de sementes na área de estudo, foram selecionados três ambientes, sendo dois degradados e um ambiente-referência (conservado) de cerrado campestre, em área adjacente ao estudo. Em cada ambiente foram coletadas 16 amostras com o auxílio de um gabarito (estrutura metálica vazada com $25 \times 25 \times 5 \mathrm{~cm}$ ), compondo por amostra um volume total de $0,003125 \mathrm{~m}^{3}$ e uma área de $0,0625 \mathrm{~m}^{2}$. As amostras foram acondicionadas em sacos plásticos pretos, identificados por etiquetas, e posteriormente transportadas para o Centro Integrado de Propagação de Mudas da Engenharia Florestal (CIPEF), da Universidade Federal dos Vales do
Jequitinhonha e Mucuri - UFVJM, onde foram passadas em uma peneira grossa $(4,0 \mathrm{~mm})$, para retirar tocos, raízes e torrões, sendo posteriormente homogeneizadas. As amostras de solo foram depositadas em bandejas plásticas de $0,004106 \mathrm{~m}^{3}$, contendo $2,0 \mathrm{~cm}$ de areia esterilizada em estufa de secagem com circulação e renovação de ar a $128{ }^{\circ} \mathrm{C}$ por uma hora, e perfuradas para facilitar a drenagem do solo. Em seguida, elas foram acondicionadas em casa de vegetação sob irrigações diárias, controladas no decorrer do experimento, mantendo-se a sua umidade próxima à capacidade de campo. Também foram depositadas dentro da casa de vegetação bandejas controle com areia esterilizada, para verificar a possibilidade de contaminação com sementes externas dentro da casa de vegetação.

A avaliação do banco de sementes do solo foi realizada por meio do método indireto, através da identificação das plântulas originadas da germinação das sementes presentes nas amostras (Baskin \& Baskin, 1989).

O procedimento de coleta das amostras de solo para o desenvolvimento do presente estudo ocorreu em duas etapas: estação seca (julho de 2010), com temperatura média máxima mensal de $21,8{ }^{\circ} \mathrm{C}$ e precipitação média de $1,8 \mathrm{~mm}$; e estação chuvosa (dezembro de 2010), apresentando temperatura média máxima mensal de $26,6{ }^{\circ} \mathrm{C}$ e precipitação média de $294,8 \mathrm{~mm}$. Assim, a contagem das plântulas oriundas do banco de sementes do solo foi feita por um período de dez meses, totalizando 22 dias de contagem e 300 dias de avaliação.

No último dia de contagem de ambas as coletas, foi realizada a identificação das plântulas emergidas, por meio de chave botânica, consultas a herbários e literatura.

Para a análise florística do banco de sementes, foram utilizados os seguintes parâmetros: indice de diversidade de ShannonWeaver $\left(\mathrm{H}^{\prime}\right)$, indice de equabilidade de Pielou (J) e indice de similaridade de Sorensen (SO).

A avaliação da emergência das plântulas foi feita durante um período de 100 dias após a instalação do experimento. $O$ índice de velocidade de emergência (IVE) (Nakagawa, 1999) e o tempo médio de germinação (Tm) (Edmond \& Drapala, 1965) foram calculados para o banco de sementes de cada ambiente, 
conforme as expressões descritas a seguir.

$$
I V E=\frac{N_{1}}{D_{1}}+\frac{N_{2}}{D_{2}}+\ldots+\frac{N_{n}}{D_{n}}
$$

em que: $I V E=$ indice de velocidade de emergência; $N_{1}=$ número de plântulas emergidas na primeira contagem; $D_{1}=$ número de dias para a primeira contagem; $N_{n}=$ número de plântulas emersas na última contagem; e $D_{n}$ = número de dias para a última contagem.

$$
\operatorname{Tm}=\frac{G_{1} T_{1}+G_{2} T_{2}+\ldots+G_{n} T_{n}}{G_{1}+G_{2}+\ldots+G_{n}}
$$

em que $T m=$ tempo médio necessário para atingir a germinação máxima; e $G_{1}, G_{2}$ e $G_{n}=$ número de sementes germinadas nos tempos $T_{1}, T_{2}$ e $T_{n}$, respectivamente.

Os dados de IVE e Tm foram submetidos a testes de normalidade, homogeneidade e variância pelo software Estatística 7.0. As médias de $I V E$ e $T m$ foram submetidas ao teste de Tukey a $5 \%$ de probabilidade.

Os dados foram analisados considerandose o delineamento inteiramente ao acaso (DIC), em esquema fatorial $3 \times 2$, sendo estudado o efeito dos três ambientes utilizados e das duas épocas de coleta do banco de sementes.

\section{RESULTADOS E DISCUSSÃO}

Durante a condução do experimento, foi garantida a não contaminação das bandejas avaliadas, uma vez que não foi observada emissão de plântulas nas bandejas controle.

Na Tabela 1, observa-se a relação das espécies encontradas no estudo do banco de sementes e suas respectivas famílias botânicas para os três ambientes, em ambas as épocas de coleta.

Foram encontradas 43 espécies em 17 famílias botânicas para as áreas de estudo, e uma espécie não foi possivel identificar. Somente Alternanthera tenella, Hypochoeris brasiliensis, Sida santaremnensis, Microlicia sp., Spermacoce latifola e Lavoisiera sp. são nativas para a área em questão; de todas as espécies listadas, somente Vernonanthura phosphorica e Tibouchina granulosa possuem forma de vida arbórea. A baixa densidade de sementes de espécies arbóreas encontradas no banco de sementes pode ser explicada pelo fato de as áreas em estudo estarem em processo inicial de sucessão ecológica e não possuírem árvores matrizes circundando-as, nem fragmentos conservados no entorno, o que dificulta a dispersão dos frutos. Saulei \& Swaine (1988) estudaram o estabelecimento do banco de sementes no solo pela chuva de sementes durante dois anos em Nova Guiné e concluíram que em floresta primária esse banco é constituído principalmente por sementes depositadas por plantas matrizes anteriormente presentes na floresta. Miranda Neto et al. (2010) não constataram a germinação de espécies arbustivo-arbóreas em clareiras testemunha, demonstrando que, possivelmente, as sementes oriundas da chuva de sementes do entorno não estavam conseguindo se estabelecer no local.

Vale ressaltar que existe tendência de redução na densidade de espécies herbáceas no banco de sementes e aumento de sementes arbustivas e arbóreas com o avanço na sucessão em florestas secundárias (Baider et al., 2001; Dalling, 2002), uma vez que, à medida que as espécies arbóreas vão se estabelecendo nesses locais, vão proporcionar maior sombreamento na área; como a maioria das espécies herbáceas é pioneira, estas tendem a desaparecer. Para isso, o enriquecimento desse banco de sementes depende, entre outros fatores, da proximidade com fragmentos conservados no entorno da área, que facilita a dispersão de sementes. Também podem ser adotadas técnicas de semeadura direta no banco de sementes, com espécies arbóreas desejáveis na restauração ambiental, acelerando assim o processo.

Na Tabela 2 encontram-se o número total de sementes germinadas e a densidade total de sementes (sementes $\mathrm{m}^{2}$ ), no banco de sementes de cada ambiente, para a coleta realizada nos períodos seco (agosto de 2010) e chuvoso (dezembro de 2010).

Para a estação seca, observa-se que 3.019 sementes germinaram no ambiente 1 e 518 no ambiente 2. Já para a estação chuvosa, observa-se que 2.614 germinaram no ambiente $1,2.771$ no ambiente 2 e 75 no ambiente 3 . 
Tabela 1 - Relação das espécies e respectivas famílias botânicas para o banco de sementes em três áreas, para as estações seca (julho de 2010) e chuvosa (outubro de 2010), em Diamantina-MG

\begin{tabular}{|c|c|c|c|c|}
\hline Família & Espécie & FV & Origem & Estação \\
\hline Acanthaceae & Justicia pectoralis Vault & $\mathrm{H}$ & EXO & $\mathrm{S}, \mathrm{C}$ \\
\hline \multirow{3}{*}{ Amaranthaceae } & Alternanthera tenella Colla & $\mathrm{H}$ & NAT & $\mathrm{C}$ \\
\hline & Amaranthus spinosus L. & $\mathrm{H}$ & EXO & $\mathrm{S}, \mathrm{C}$ \\
\hline & Aramanthus hybridus var. patulos (Betol.) Thell & $\mathrm{H}$ & EXO & $\mathrm{S}$ \\
\hline \multirow{10}{*}{ Asteraceae } & Acanthospermum australe (Loefl.) Kuntze & $\mathrm{H}$ & $\mathrm{EXO}$ & $\mathrm{S}, \mathrm{C}$ \\
\hline & Bidens pilosa $\mathrm{L}$. & $\mathrm{H}$ & EXO & $\mathrm{C}$ \\
\hline & Bidens subalternans DC. & $\mathrm{H}$ & EXO & $\mathrm{S}, \mathrm{C}$ \\
\hline & Chenopodium ambrosioides L. & $\mathrm{H}$ & EXO & $\mathrm{S}$ \\
\hline & Conyza canadensis $\mathrm{L}$. & $\mathrm{H}$ & EXO & $\mathrm{C}$ \\
\hline & Emilia fosbergii Nicolson & $\mathrm{H}$ & EXO & $\mathrm{S}, \mathrm{C}$ \\
\hline & Galinsoga quadriradiata Ruiz \& Pav. & $\mathrm{H}$ & EXO & $\mathrm{S}$ \\
\hline & Hypochoeris brasiliensis (Less.) Griseb. & $\mathrm{H}$ & NAT & $\mathrm{S}$ \\
\hline & \begin{tabular}{|l} 
Siegesbeckia orientalis L. \\
\end{tabular} & $\mathrm{H}$ & - & $\mathrm{S}$ \\
\hline & \begin{tabular}{|l|} 
Vernonanthura phosphorica (Vell.) H.Rob. \\
\end{tabular} & $\mathrm{A}$ & EXO & $\mathrm{C}$ \\
\hline Brassicaceae & Lepidium virginicum $\mathrm{L}$. & $\mathrm{H}$ & $\mathrm{EXO}$ & $\mathrm{C}$ \\
\hline Cyperaceae & Cyperus sp. & $\mathrm{H}$ & EXO & $\mathrm{S}, \mathrm{C}$ \\
\hline \multirow{2}{*}{ Euphorbiaceae } & Euphorbia heterophylla L. & $\mathrm{H}$ & EXO & $\mathrm{C}$ \\
\hline & Ricinus communis $\mathrm{L}$. & $\mathrm{AR}$ & EXO & $\mathrm{C}$ \\
\hline Fabaceae - Caesalpinioideae & Senna obtusifolia (L.) H.S Irwin \& Barneby & SAR & EXO & $\mathrm{S}, \mathrm{C}$ \\
\hline \multirow{2}{*}{ Fabaceae - Faboideae } & Aeschynomene dendiculata Rudd & $\mathrm{AR}$ & EXO & $\mathrm{S}$ \\
\hline & Desmodium tortuosum (Sw.) DC & $\mathrm{H}$ & EXO & $\mathrm{S}, \mathrm{C}$ \\
\hline \multirow{3}{*}{ Malvaceae } & Sida rhombifolia L. & SAR & EXO & $\mathrm{S}, \mathrm{C}$ \\
\hline & \begin{tabular}{|l|} 
Sida santaremnensis H. Monteiro \\
\end{tabular} & SAR & NAT & $\mathrm{C}$ \\
\hline & Sidastrum micranthum (A. St.-Hil.) & SAR & EXO & $\mathrm{C}$ \\
\hline \multirow{3}{*}{ Melastomataceae } & Lavoisiera $\mathrm{sp}$. & $\mathrm{H}$ & NAT & $\mathrm{C}$ \\
\hline & \begin{tabular}{|l|} 
Microlicia sp. \\
\end{tabular} & $\mathrm{H}$ & NAT & $\mathrm{C}$ \\
\hline & Tibouchina granulosa (Desr.)Cogn. & $\mathrm{AR}$ & EXO & $\mathrm{C}$ \\
\hline Oxalidaceae & Oxalis corniculata L. & $\mathrm{H}$ & EXO & $\mathrm{S}$ \\
\hline \multirow{9}{*}{ Poaceae } & Urochloa decumbes (Stapf) RD, Wabster & & EXO & $\mathrm{S}, \mathrm{C}$ \\
\hline & Brachiaria plantaginea (Link) Hitchc. & $\mathrm{H}$ & EXO & $\mathrm{C}$ \\
\hline & Cenchrus echinatus $\mathrm{L}$. & $\mathrm{H}$ & EXO & $\mathrm{S}$ \\
\hline & Digitaria sanguinalis (L.) Scop. & $\mathrm{H}$ & EXO & $\mathrm{C}$ \\
\hline & Eleusine indica (L.) Gaertn. & $\mathrm{H}$ & EXO & $\mathrm{S}, \mathrm{C}$ \\
\hline & Lolium multiflorum Lam. & $\mathrm{H}$ & EXO & $\mathrm{C}$ \\
\hline & Melinis minutiflora P. Beauv. & $\mathrm{H}$ & EXO & $\mathrm{S}, \mathrm{C}$ \\
\hline & Panicum maximum Jacq. & & EXO & $\mathrm{C}$ \\
\hline & Sorghum arundinaceum (Desv.) Stapf & $\mathrm{H}$ & EXO & $\mathrm{S}$ \\
\hline Portulacaceae & Portulaca oleracea L. & $\mathrm{H}$ & EXO & $\mathrm{S}, \mathrm{C}$ \\
\hline \multirow{2}{*}{ Rubiaceae } & Diodia teres Walter & $\mathrm{H}$ & EXO & $\mathrm{S}, \mathrm{C}$ \\
\hline & Spermacoce latifola Aubl. & $\mathrm{H}$ & NAT & $\mathrm{S}, \mathrm{C}$ \\
\hline \multirow{3}{*}{ Solanaceae } & Nicandra physaloides (L.) Pers. & $\mathrm{H}$ & EXO & $\mathrm{C}$ \\
\hline & \begin{tabular}{|l|} 
Solanum americanum Mill. \\
\end{tabular} & $\mathrm{H}$ & EXO & $\mathrm{C}$ \\
\hline & Espécie não identificada & $\mathrm{H}$ & EXO & $\mathrm{S}, \mathrm{C}$ \\
\hline
\end{tabular}

FV (forma de vida); A (arbórea); AR (arbustiva); H (herbácea); SAR (subarbustiva); EXO (exótica); NAT (nativa); S (seca); C (chuvosa). 
A maior parte das sementes germinadas para os ambientes 1 e 2 (ambientes degradados), em ambas as épocas de coleta, foram identificadas como invasoras na área de estudo; destas, as espécies mais representativas foram Melinis minutiflora, Urochloa decumbens e Cyperus sp. Juntas, as famílias Cyperaceae e Poaceae representam, para as duas estações de coleta, 19,25 e $45,28 \%$ dos indivíduos regenerados, respectivamente, contribuindo com $64,03 \%$ do total de indivíduos coletados. Características inerentes à sua biologia contribuíram para seu sucesso como invasoras em ambiente de cerrado perturbados ou degradados: são heliófilas e possuem metabolismo $\mathrm{C}_{4}$, sendo adaptadas para colonizar áreas abertas e ensolaradas, como os campos e cerrados brasileiros; têm alta eficiência fotossintética e na utilização dos nutrientes, sobrevivendo em solos menos férteis; apresentam alta taxa de crescimento, rebrotamento e regeneração, além de alta tolerância à herbivoria; sua eficiência reprodutiva se deve ao ciclo reprodutivo rápido, à intensa produção de sementes com alta viabilidade, que formam um banco de sementes denso, à alta capacidade de dispersão por sementes anemocóricas e por reprodução vegetativa e à alta capacidade de germinação. Essas características permitem a essas espécies um comportamento oportunista, que permite a rápida recolonização de áreas antropizadas, possibilitando competir com vantagem e deslocar espécies nativas do cerrado (Coutinho, 1982; Baruch et al., 1985; Pivello et al., 1999).

Em estudo realizado por Rondon Neto et al. (2011), as famílias botânicas com maior número de indivíduos regenerados foram Cyperaceae $(54,0 \%)$ e Poaceae $(23,9 \%)$, as quais contribuíram com $77,9 \%$ do total de individuos.

Segundo Grime (1979), plantas ruderais habitam áreas de alta intensidade de distúrbio, bastante irrigadas e adubadas, possuem rápido ciclo de desenvolvimento, alta produção de propágulos e se caracterizam por sua alta agressividade ao ecossistema. Segundo Souza et al. (2006), a ausência ou não continuidade de um dossel nessas áreas facilita a entrada de sementes de espécies invasoras e sua incorporação no solo.

$\mathrm{O}$ número médio de sementes $\mathrm{m}^{2}$ encontrado na coleta em período chuvoso, para os ambientes degradados 1 e 2, foi de 3.802,18 e $4.030,55$ sementes $\mathrm{m}^{2}$, respectivamente. Esses valores são superiores em comparação aos de outros trabalhos com banco de sementes mesmo em área de pasto, como os de Araújo et al. (2001), que encontraram uma densidade de 2.848 sementes $\mathrm{m}^{-2}$ de sementes de gramínea em área de pasto na Amazônia ocidental, e Randon Neto \& Silva, que avaliaram o banco de sementes de um remanescente florestal e

Tabela 2 - Total de sementes por data de coleta, média e número total de sementes por $\mathrm{m}^{2}$ em três ambientes de cerrado, para as estações seca (julho de 2010) e chuvosa (outubro de 2010), em Diamantina-MG

\begin{tabular}{|c|c|c|c|c|c|c|c|}
\hline \multirow{2}{*}{ Estação } & \multicolumn{3}{|c|}{ Seca } & & \multicolumn{3}{|c|}{ Chuvosa } \\
\hline & \multicolumn{3}{|c|}{ Ambiente } & & \multicolumn{3}{|c|}{ Ambiente } \\
\hline Dias & 1 & 2 & 3 & & 1 & 2 & 3 \\
\hline 30 & 718 & 39 & 0 & & 949 & 1.697 & 0 \\
\hline 37 & 54 & 0 & 0 & & 592 & 598 & 0 \\
\hline 41 & 243 & 189 & 0 & & 195 & 76 & 20 \\
\hline 62 & 110 & 82 & 0 & & 236 & 121 & 8 \\
\hline 69 & 359 & 50 & 0 & & 169 & 64 & 4 \\
\hline 79 & 357 & 46 & 0 & & 186 & 58 & 5 \\
\hline 89 & 32 & 0 & 0 & & 101 & 42 & 7 \\
\hline 100 & 158 & 26 & 0 & & 105 & 39 & 4 \\
\hline 111 & 340 & 39 & 0 & & 36 & 49 & 5 \\
\hline 126 & 348 & 32 & 0 & & 17 & 4 & 4 \\
\hline 146 & 300 & 15 & 0 & & 28 & 23 & 18 \\
\hline Média & 274,45 & 47,09 & 0 & Média & 237,64 & 251,91 & 6,82 \\
\hline No total sementes & 3.019 & 518 & 0 & № total sem & 2.614 & 2.771 & 75 \\
\hline № médio sem. m ${ }^{-2}$ & 4391,27 & 753,45 & 0 & № médio sem. $\mathrm{m}^{-2}$ & 3802,18 & 4030,55 & 109,09 \\
\hline
\end{tabular}


duas áreas de pastagens, com idades de $17 \mathrm{e}$ 27 anos, no município de Alta Floresta-MT e encontraram densidades de sementes variando de 89 a 448 sementes $\mathrm{m}^{-2}$.

Verifica-se baixa densidade de sementes germinadas para o ambiente 3 (Tabela 2); na coleta da estação seca não houve germinação nele e, para a coleta da estação chuvosa, $38,67 \%$ das sementes germinadas foram de espécies nativas para a área de estudo, a saber: Lavoisiera sp., Microlicia sp., Spermacoce latifola e Sida santaremnensis. A baixa densidade de germinação do ambiente 3, comparada à dos demais, pode ser explicada pelo fato de esse ambiente possuir considerável estado de conservação, inibindo a entrada de espécies invasoras na área, como proposto pelo modelo de inibição descrito por Connell \& Slatyer (1977). O essencial nesse modelo é que as espécies invasoras iniciais somente serão capazes de colonizar esses ambientes, uma vez que distúrbios locais têm progressivamente levado à morte das espécies nativas (Ward \& Jennings 1990). Se os distúrbios são infrequentes, as espécies dominantes ocupam os recursos e eliminam fracos competidores (Connell, 1978).

A menor densidade observada para a estação seca no ambiente 2 (Figura 1) deve-se ao fato de ele possuir menor número de indivíduos de capim-gordura, quando comparado ao ambiente 1. Isso porque, no período da coleta, as plantas de capim-gordura apresentavamse em pleno estádio de dispersão de sementes; logo, era esperado encontrar maior número

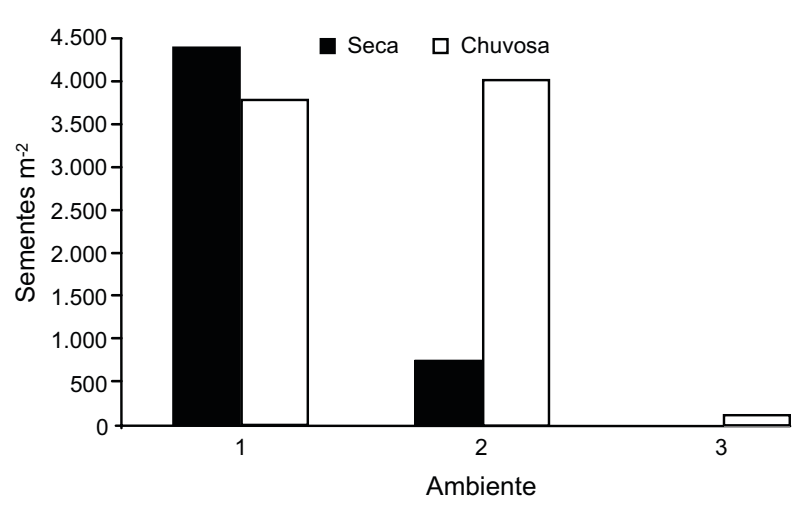

Figura 1 - Densidade média de sementes germinadas (sementes $\mathrm{m}^{-2}$ ) no banco de sementes para três ambientes de cerrado, durante as estações seca (julho de 2010) e chuvosa (outubro de 2010), em Diamantina-MG. de sementes possivelmente viáveis para o ambiente 1 .

Na Figura 2 é apresentada a regressão pelo método dos mínimos quadrados ordinários para a germinação cumulativa do número de sementes nos três ambientes, para as duas épocas de coleta. Nota-se que houve inversão no número de sementes germinadas para os ambientes degradados ( 1 e 2 ) nas diferentes épocas de coleta, sendo esse fenômeno explicado pela descontinuidade de germinação das espécies entre os ambientes estudados.

A densidade do banco de sementes varia muito de um local para outro, mas tende a ser maior em florestas secundárias, onde o dossel mais aberto possibilita maior densidade de espécies pioneiras, cujas sementes possuem dormência e formam banco persistente (Baider et al., 1999).

Os indices de diversidade de Shannon e o indice de equabilidade de Pielou, para os três ambientes de estudo, são apresentados na
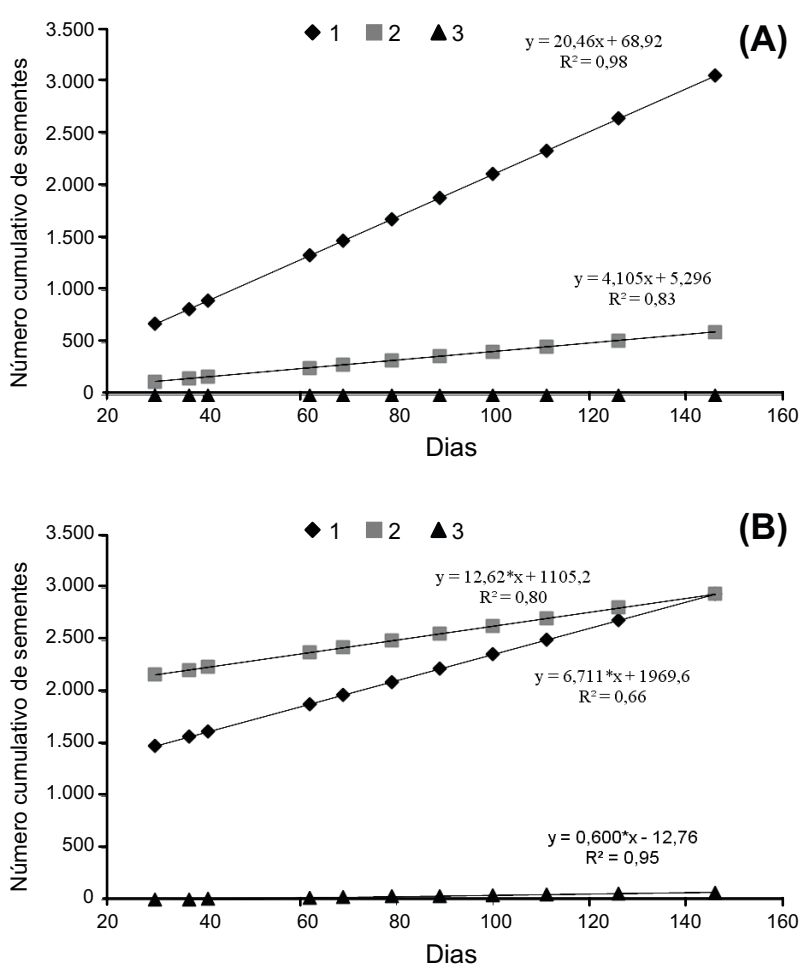

1 (ambiente 1), 2 (ambiente 2) e 3 (ambiente 3); A (coleta da estação seca) e B (coleta da estação chuvosa). * p $<0,05$.

Figura 2 - Número cumulativo de sementes germinadas para os ambientes estudados, para as duas estações de coleta. 
Tabela 3. Observa-se maior indice de diversidade de Shannon-Weaver ( $\left.\mathrm{H}^{\prime}\right)$ para o ambiente 3 (ambiente-referência), o que indica o seu maior grau de conservação. A equabilidade de Pielou ( $\left.\mathrm{J}^{\prime}\right)$, para o ambiente 3, foi elevada comparada à dos demais ambientes, indicando que nesse ambiente há maior número de indivíduos dominantes para a área estudada.

Apesar da dificuldade de comparações de indices de diversidade, os valores encontrados neste trabalho são similares aos reportados para banco de sementes. Em áreas degradadas de cerrado sensu stricto, Ikeda et al. (2008) encontraram valores de diversidade para áreas de cerrado pós-ocorrência do fogo e área de lavoura de 1,27 e 1,94, respectivamente. Já em remanescente natural de mata ciliar ripária, Nóbrega et al. (2009) encontraram um indice de diversidade de 2,25 e equabilidade de 0,75 - valores próximos aos encontrados para o ambiente 3 (ambiente-referência).

A similaridade entre os ambientes para as diferentes épocas de coleta é mostrada na Tabela 4. Observa-se que não foi possivel fazer analogias para o ambiente 3 na coleta da estação seca, pois para ele não houve germinação de nenhum indivíduo. De acordo com MuellerDombois \& Ellenberg (1974), podem-se

Tabela 3 - Valores de diversidade e equabilidade para um banco de sementes em três ambientes de cerrado, nas estações seca (julho de 2010) e chuvosa (outubro de 2010), em Diamantina-MG

\begin{tabular}{|c|c|c|c|c|}
\hline \multirow{2}{*}{ Ambiente } & \multicolumn{2}{|c|}{ Seca } & \multicolumn{2}{c|}{ Chuvosa } \\
\cline { 2 - 5 } & $\mathrm{H}^{\prime}$ & $\mathrm{J}^{\prime}$ & $\mathrm{H}^{\prime}$ & $\mathrm{J}^{\prime}$ \\
\hline 1 & 1,941 & 0,603 & 1,883 & 0,571 \\
\hline 2 & 1,821 & 0,657 & 1,830 & 0,576 \\
\hline 3 & - & - & 2,337 & 0,825 \\
\hline
\end{tabular}

$\mathrm{H}^{\prime}=$ índice de diversidade de Shannon e $\mathrm{J}^{\prime}=$ índice de equabilidade de Pielou. considerar duas comunidades floristicamente similares quando o índice de Sorensen é igual ou superior a 0,50 , o que foi evidenciado com os valores de 0,810 entre os ambientes 1 e 2 para a coleta da estação seca e de 0,941 entre os mesmos ambientes para a coleta da estação chuvosa. A similaridade entre os ambientes 1 e 2 pode ser explicada pelo fato de eles se apresentarem localizados próximos geograficamente e, também, por suas semelhanças quanto ao histórico de degradação.

O efeito em nivel de interação apresentouse significativo somente para o tempo médio necessário para atingir a germinação máxima (Tm) (Tabela 5); já o indice de velocidade de emergência (IVE) mostrou diferenças significativas para os ambientes e épocas de coleta (estações seca e chuvosa).

Nota-se, nas Tabelas 5 e 6, que o IVE e o Tm para a estação chuvosa diferem significativamente a $5 \%$ de probabilidade do IVE e Tm para a estação seca, comprovando a maior emergência das plântulas - principalmente as invasoras - no período chuvoso. Vale ressaltar que as quatro espécies arbóreas identificadas no presente estudo germinaram no banco de semente da coleta da estação chuvosa. Assim, a estação chuvosa é a estação recomendada para a coleta do banco quando se tem o objetivo de utilizá-lo na recuperação de áreas degradadas, porém outros fatores devem ser observados para a tomada de decisão, como o número de sementes de espécies invasoras contidas no banco de sementes.

Na Tabela 6 é apresentado o desdobramento do grau de liberdade da interação entre ambiente e estação de coleta, para a variável Tm do banco de sementes.

Cabe ressaltar que em áreas degradadas com grande presença de gramineas exóticas, como a do presente estudo, o simples isolamento da área não garante a regeneração

Tabela 4 - Matriz de índices de similaridade de Sorensen (SO), estimada para o banco de sementes dos ambientes estudados, para as coletas das estações seca e chuvosa

\begin{tabular}{|c|c|c|c|c|c|c|}
\hline \multirow{2}{*}{ Ambiente } & \multicolumn{3}{|c|}{ Estação seca (julho 2010) } & \multicolumn{3}{c|}{ Estação chuvosa (outubro 2010) } \\
\cline { 2 - 7 } & 1 & 2 & 3 & 1 & 2 & 3 \\
\hline 1 & - & 0,810 & 0,000 & - & 0,941 & 0,591 \\
\hline 2 & 0,810 & - & 0,000 & 0,941 & - & 0,585 \\
\hline 3 & 0,000 & 0,000 & - & 0,591 & 0,585 & - \\
\hline
\end{tabular}


Tabela 5 - Teste de Tukey para as médias de IVE do banco de sementes, para os três ambientes e para as estações de coleta

\begin{tabular}{|c|c|l|c|}
\hline Ambiente & Média de IVE & Estação & Média de IVE \\
\hline 1 & $3,64 \mathrm{a}$ & Chuvosa & $2,95 \mathrm{a}$ \\
\hline 2 & $2,37 \mathrm{a}$ & Seca & $1,27 \mathrm{ab}$ \\
\hline 3 & $0,30 \mathrm{ab}$ & & \\
\hline
\end{tabular}

Médias seguidas da mesma letra na linha não diferem estatisticamente pelo teste de Tukey a $5 \%$.

Tabela 6 - Desdobramento do grau de liberdade da interação (ambiente x estação) para a variável Tm do banco de sementes, para os três ambientes e para as estações de coleta

\begin{tabular}{|l|c|c|c|}
\hline \multirow{2}{*}{ Estação } & \multicolumn{3}{|c|}{ Média de Tm } \\
\cline { 2 - 4 } & 1 & 2 & 3 \\
\hline Seca & $76,10 \mathrm{aA}$ & $58,46 \mathrm{aA}$ & $0,00 \mathrm{bB}$ \\
\hline Chuvosa & $55,09 \mathrm{bB}$ & $50,76 \mathrm{aB}$ & $90,43 \mathrm{aA}$ \\
\hline
\end{tabular}

$\mathrm{Tm}$ = tempo médio necessário para atingir a germinação máxima. Médias seguidas da mesma letra minúscula na linha e maiúscula na coluna não diferem estatisticamente pelo teste de Tukey a $5 \%$.

natural, sendo necessário proceder ao manejo adequado dessas espécies daninhas e utilizar outros métodos de recuperação para restauração do ambiente. A utilização de um banco de sementes pode ser uma técnica viável, porém ele deve ser avaliado antes do seu uso. Um banco de sementes "rico" em espécies arbóreas pode até mesmo inibir o desenvolvimento das gramíneas exóticas. Em trabalho realizado por Miranda Neto et al. (2010), a cobertura das clareiras com o banco de sementes do solo inibiu o desenvolvimento de Melinis minutiflora.

Conclui-se que o banco de sementes estudado é formado basicamente por espécies herbáceas com caráter invasor, não contendo sementes de espécies arbustivo-arbóreas depositadas. Nesse sentido, o banco de sementes do solo local não é suficiente para que haja recuperação por meio da sucessão ecológica dessas áreas, sendo recomendando o uso de técnicas visando acelerar a restauração desses ambientes.

\section{AGRADECIMENTO}

Os autores agradecem à Fundação de Amparo à Pesquisa no Estado de Minas Gerais/FAPEMIG, pelo apoio Financeiro à realização da Pesquisa.

\section{LITERATURA CITADA}

ARAÚJO, M. M. et al. Densidade e composição florística do banco de sementes do solo de florestas sucessionais na região do Baixo Rio Guamá, Amazônia Oriental. Sci. For., v.59, n. 1, p. $115-130,2001$.

BAIDER, C. et al. O banco de sementes de um trecho de uma Floresta Atlântica Montana (São Paulo - Brasil). R. Bras.

Biol., v. 59, n. 2, p. 319-328, 1999.

BAIDER, C. et al. The soil seed bank during Atlantic forest regeneration in Southeast Brazil. R. Bras. Biol., v. 61, n. 1, p. $35-44,2001$

BARUCH, Z.; LUDLOW, M. M.; DAVIS, R. Photosynthetic responses of native and introduced $\mathrm{C}_{4}$ grasses from Venezuelan savannas. Oecologia, v. 67, n. 3, p. 388-393, 1985.

BASKIN, J. M.; BASKIN, C. C. Physiology of dormancy and germination in relation to seed bank ecology. In LECK, M. A.; PARKER, V. T.; SIMPSON, R. L.; (Eds.). Ecology of soil seed bank. London: Academic Press, 1989. p. 53-65.

CALDATO, S. L. et al. Estudo da regeneração natural, banco de sementes e chuva de sementes na reserva genética florestal de Caçador. Ci. Flor., v. 6, n. 1, p. 27-38, 1996.

CARMONA, R. Problemática e manejo de bancos de sementes de invasoras em solos agrícolas. Planta Daninha, v. 10, n. 1, p. $5-16,1992$.

CONNELL, J. H.; SLATYER, R. O. Mechanisms of succession in natural communities and their role in community stability and organization. Am. Natur., v. 111, n. 982, p. 1119-1144, 1977.

CONNELL, J. H. Diversity in tropical rain forests and coral reefs - high diversity of trees and corals is maintained only in a non-equilibrium state. Science, v. 199, n. 8, p. 1302-1310, 1978.

COSTALONGA, S. R. et al. Florística do banco de sementes do solo em áreas contíguas de pastagem degradada, plantio de eucalipto e floresta em Paula Cândido, MG. Floresta, v. 36, n. 2, p. 239-250, 2006.

COUTINHO, L. M. Aspectos ecológicos da saúva no cerrado - os murundus de terra, as características psamofíticas das espécies de sua vegetação e a sua invasão pelo capim-gordura. R. Bras. Bot., v. 42, n. 1, p. 147-153, 1982.

DALLING, J. W. Ecología de semillas. In: GUARIGUATA, M. R.; KATTAN, G. H. (Eds.). Ecología y conservación de bisques neotropicales. Cartago: Libro Universitario Regional, 2002. p. $345-375$.

Planta Daninha, Viçosa-MG, v. 31, n. 2, p. 303-312, 2013 
EDMOND, J. B.; DRAPALA, W. J. The effects of temperature, sand and soil, and acetone on germination of okra see d. Proc. Am. J. Soc. Hortic. Sci., v. 71, n. 3, p. 428-434, 1965.

FELFILI, J. M.; SILVA JÚNIOR, M. C. Biogeografia do bioma cerrado: estudo fitofisionômico da Chapada do Espigão Mestre do São Francisco. Brasília: UNB, 2001. $152 \mathrm{p}$.

GRIME, J. P. Estrategias de adapatación de las plantas y procesos que controlan la Vegetación. Mexico, D.F.: Noriega, 1979. p. 79-87.

IKEDA, F.S. et al. Banco de sementes em cerrado sensu stricto sob queimada e sistemas de cultivo. Pesq. Agropec. Bras., v. 43, n. 6, p. 667-673, 2008

MIRANDA NETO, A. et al. Transposição do banco de sementes do solo como metodologia de restauração florestal de pastagem abandonada em Viçosa, MG. R. Árvore, v. 34, n. 6, p. $1035-1043,2010$

MUELLER-DOMBOIS, D.; ELLENBERG, H. A. Aims and methods of vegetation ecology. New York: John Wiley, 1974. $547 \mathrm{p}$.

NAKAGAWA, J. Testes de vigor baseados no desempenho das plântulas. In: KRZYZANOWSKI, F. C.; VIEIRA, R. D.; FRANÇA NETO, J. B. Vigor de sementes: conceitos e testes. Londrina: ABRATES, 1999. p. 2.1-2.24.

NÓBREGA, A. M. F. et al. Banco de sementes de remanescentes naturais e de áreas reflorestadas em uma várzea do rio Mogi-Guaçu. R. Árvore, v. 33, n. 3, p. 403-411, 2009.

NOGUEIRA, J. C. B.; NOGUEIRA, L. T. Regeneração natural de mata ciliar na Estação Ecológica de Bauru. R. Instituto Flor., v. 3, n. 2, p. 157-162, 1991.

PÉREZ, E. M.; SANTIAGO, E. T. Dinámica estacional del banco de semillas en una sabana en los Lhanos CentroOrientales de Venezuela. Biotropica, v. 33, n. 3, p. 435-446, 2001.

PIVELLO, V. R. et al. Alien grasses in Brazilian savannas: a threat to biodiversity. Biodiversity Conserv., v. 8, n. 1, p. 1281-1294, 1999
POTT, A. et al. Plantas daninhas de pastagem na região dos Cerrados. Campo Grande: Embrapa Gado de Corte, 2006. $336 \mathrm{p}$.

PRICE, M. V.; JOYNER, J. W. What resources are available to desert granivores: Seed rain or soil seed bank? Ecology, v. 78 , n. 6, p. $764-773,1997$

RIBEIRO, J. F.; WALTER, B. M. T. As principais fitofisionomias do bioma Cerrado. In: SANO, S. M.; ALMEIDA, S. P.; RIBEIRO, J. F. (Ed.). Cerrado: ecologia e flora. Brasília, DF: Embrapa Informação Tecnológica, 2008. v. 2. p. $151-212$

RONDON NETO, R. M.; SILVA, D. F. Banco de sementes de um remanescente florestal e duas áreas de pastagem de diferentes idades, em Alta Floresta/MT. R. Bras. Ci. Agr., v. 6, n. 1, p. 113-120, 2011

SANO, E. E. et al. Metodologias para mapeamento de pastagens degradadas no Cerrado. Planaltina: Embrapa Cerrados, 2002. 22 p. (Embrapa Cerrados. Boletim de Pesquisa e Desenvolvimento, 70).

SAULEI, S. M.; SWAINE, M. D. Rain forest seed dynamics during succession at Gogol, Papua-Nova Guiné. J. Ecol., v. 62, n. 4 , p. $1133-1152,1988$.

SIMPSON, R. L. et al. Seed banks: General concepts and methodological issues. In: LECK, M. A.; PARKER, V. T.; SIMPSON, R. L. (Ed). Ecology of soil seed banks. London: Academic Press, 1989. p. 3-8.

SOUZA, P. A. et al. Avaliação do banco de sementes contido na serapilheira de um fragmento florestal visando recuperação de áreas degradadas. Cerne, v. 12, n. 1, p. 56-67, 2006

van der VALK, A. G.; PEDERSON, R. L. Seed bank and managenent and restoration of natural vegetation. In LECK, M. A.; PARKER, V. T.; SIMPSON, R. L. Ecology of soil seed banks. San Diego: Academic, 1989. p. 329-346.

WARD, L. K.; JENNINGS, R. D. Sucession of disturbed and undisturbed chalk grassland at Aston Rowant National Nature Reserve: dynamics of species changes. J. Appl. Ecol., v. 27, n. 3, p. 897-912, 1990.

WELLING, C. H. et al. Recruitment from the seed bank and the development of emergent zonation during a drawdown in a prarie wetland. J. Ecol., v. 76, n. 2, p. 487-496, 1988 